\title{
A mathematical model for a reverse logistic system of chemical remanufacturing PET waste with supply uncertainty: A case study of Tehran recycling organization
}

\author{
Fahimeh Mollaei $^{a^{*}}$ and Ahmad Makui ${ }^{\mathrm{b}}$
}

${ }^{a}$ Department of Industrial Engineering, Industrial Management Institute, Tehran, Iran

${ }^{b}$ Department of Industrial Engineering, Iran University of Science and Technology, Narmak, Tehran, Iran

\section{CHRON I C L E ABSTRACT}

Article history:

Received January 12, 2013

Received in revised format

10 June 2013

Accepted June 192013

Available online

June 202013

Keywords:

Reverse logistic

PET (Polyethylene terephthalat)

waste

Chemical remanufacturing

Nonlinear probable planning

\begin{abstract}
During the past two decades, there has been a growing concern on environmental issues around the world. Firms try to provide better production plans to recycle their used materials to reduce pollution from environment. In fact, lack of management in municipal solid waste for methods of collecting, disposal and processing of them can be significant damage to the environment, This paper presents a mathematical model for pet waste management, which plays essential role on municipal solid waste. The modeling formulation is a nonlinear probable mathematical programming model for chemical recycling the PET waste. In this model, the optimal amount of waste is determined by considering collected operations of reverse logistics and chemical recycling when demand is under uncertainty.
\end{abstract}

\section{Introduction}

New developments in new millennium together with increased population and enhanced technology have given rise to the new phase of nature and environment destruction. Industrial revolution intended for the improvement of human life has created great nuisance to the environment due to the increase in production and consumption. Over the past century known, with the development and improved civilization of human being, our planet has incurred considerable damages (Rhyner et al., 1995).These days, tons of municipal waste and many other poisonous and dangerous substances resulted from daily activities of human have caused broad pollution in the environment. Collection and disposal of waste materials, with the history of more than 6000 years, are considered as necessary activates to observe particular rules and regulation. On the other hand, recycling and reusing of waste material justifies the exorbitant cost of waste disposal (Rhyner et al., 1995).

* Corresponding author. Tel: +989125095042

E-mail addresses: fahime.mollaei@yahoo.com (F. Mollaei)

(c) 2013 Growing Science Ltd. All rights reserved. doi: $10.5267 /$ j.uscm.2013.06.001 
Economy is considered as one of the most effective factors in recycling and reusing of waste materials. Significant and effective increase of oil and petrochemicals price has encouraged most countries to explore the possibilities for recycling and reusing of materials to restrain oil price. Industrial countries are seeking for methods to boost their independence and to increase oil imports. Reviewing of locations for the recycling and reusing of materials is our primary concern to help us reduce raw materials usage. Therefore, waste material considered for recycling should be well reused (Omrani, 2010). Hence, proper and scientific management of municipal solid wastes and their conversion to valuable products play essential role on production planning. Reverse logistics and other effective approaches may be used to tackle this problem.

Liste and Dekker (2005) presented a combined stochastic integer planning model aimed at maximizing profit through by considering uncertainty as well as type and quality of recycled products which is one of the most significant elements in designing of a reverse logistics network, in a stone recycling network. They solved the resulted model under different modes taking into account different scenarios. Aras et al. (2008) provided a non-linear model to determine the location for collection, disposal and recovery in reverse logistics.

Ramezani et al. (2012) offered a multi-purpose stochastic model to design a reverse logistics network in uncertainty condition. Bautista and Pereira (2006) expressed that municipal waste could be viewed as reverse logistics issues. Zhang et al. (2011) proposed an uncertain reverse logistics model to manage municipal solid wastes. Ahluwalia and Nema (2006) presented a multi-purpose reverse logistics to design a computerized system for waste management in order to select the optimum configuration to manage facilities and allocation of waste materials to each facility. Sheu (2007) provided an integrated management system for reverse logistics in a production setting with high technology for the recycling of harmful wastes.

Since PET recycling management can be viewed as a reverse logistics, this study provides a mathematical model to manage some proportions of the municipal solid wastes. Current study aims at providing a mathematical model for the reverse logistics system of recycling PET polymers in municipal solid waste. This model enables us to manage some proportion of valuable municipal wastes, effectively. Based on the previous studies, no specific research has been conducted on the given subject. Results from this model may greatly assist the process of PET recycling. In this paper, recycle and reuse are deemed to have the same meaning).

\section{Waste materials}

Waste materials are referred to as cheap or valueless materials from the viewpoint of producers or consumers of a society and most of the human activates eventuate in generation of waste materials. Solis waste are produced during the extraction of raw materials, refining processes and after the use of products by consumers (Abduli, 2008). Apart from the type of produced waste, individuals and state organization and agencies are responsible for finding new solutions to minimize waster production, control the dissipation of harmful substances and recycle of materials and energy from waste. Furthermore, waste disposal should be arranged so that human health will not jeopardized and environmental damages are minimized (Abduli, 2008).

Furthermore, costs of waste disposal have been considerably increased in recent years. Despite difficulties and high costs, most citizens willingly support recycling activities in favor of maintenance of resources and improvement of environment. This, in turn, leads to the fading of solutions and new markets for products made from recycled materials (Abduli, 2008).

\subsection{Waste Management}

Management of waste materials produced by human has been focused on annoying factors and the possibility for causing undesired effects on human health. Industrial revolution era together with 
growing population led to the increased problems relating to the environment pollution first in Europe and then in US. Level and depth of concerns culminated when people realized the association between contagious diseases and waste materials left in their surroundings (Rhyner et al., 1995). Even large firms were unable to prevent damages resulted from industrial revolution. Communal orientation, therefore, was necessary to escape from annoying and pathogenic factors and then demand for development of health services increased. Thus, various civil health services such as collection and disposal of waste materials, cleaning of streets and wastewater collection and treatment have emerged (Rhyner et al., 1995).

Many economic developments in western countries and in a number of other countries have led to changes in amount and composition of solid wastes. Moreover, in the current century, waste management perspective has also changed, which is basically due to the emergence of environmental movements in the $17 \mathrm{~s}$. This new perspective imply that waste management would not be feasible without taking into account the annoying factors and harmful effect of waste materials on human health. Depletion of natural resources and environment protection are another concerns of new century. Recycling of recourses, therefore, is considered as one of the main elements of municipal waste management (Rhyner et al., 1995).

\subsection{Municipal solid waste}

Municipal solid waste includes items such as durable and non-durable goods and materials, packaging containers and materials, food waste, foliage and tree wastes and other organic and inorganic substances left in residential, commercial, office and industrial areas (Rhyner et al., 1995).

\subsection{Recycled PET}

PET is a resistant substance made from polyester used in containers of fruit juices, alcoholic beverages, water, oil, hygienic cleaner and other edible and non-edible materials. PET molecules, like other polymers, are made by long chains of carbon, oxygen and hydrogen (Abduli, 2008). Pet was first used for the production of synthetic fibers. Although it was considered for packaging industry in 1960, however, its application in ordinary bottles did not start until 1970. Currently its prominent application is for making bottles (Abduli, 2008).

Other advantage of PET is its recyclability, which is of great important in terms of environment. This property was first considered in 1977 and soon after textile industries started to use PET in the production of textile, carpet and other products (Abduli, 2008). PET containers are one hundred percent recyclable. In general, recyclability of these containers is not the only reason, which makes them environmentally distinctive. They are also very light and therefore require little space during shipment. Less fuel is also required during their transport and therefore energy will be saved in this way. PET is recycled in three ways:

- Primary recycling (physical or mechanical recycling): this includes production and marketing of similar product,

- Secondary recycling (chemical reproduction): this includes plastic product processing and manufacturing.

- Plastic burring: this is basically a complementing process in which plastic materials convert to carbon dioxide and heat through the burning operation? In general, most plastics are made from thermoplastic and can be recycling again through the heating process. 


\section{Methodology}

Since a particular case namely PET in Tehran waste solid materials are used in this study, it would be a case study and since mathematical modeling has been used for this subject, it would also be a modeling study. Ultimately, it involves field study because it employs actual data of Waste Management Organization of Tehran Municipality.

\subsection{Phases of deriving a mathematical model}

In order to derive a mathematical model, statistics for collected waste materials in a specific period was required. Therefore, we used the statistics for total collected waste materials in Tehran in 2011. 12 values figures accessible for each value of total collected waste, level of dry waste and level of separated PET for all months of year. Distribution function of each value was derived using statistical analysis software in order to be used in mathematical model. Distribution functions of all these values were normal based on conducted tests in software. Table 1 demonstrates data obtained using statistical analysis in software:

Table 1

Mean and standard deviation values for obtained distribution functions

\begin{tabular}{cccc}
\hline Waste & Total collected waste $(\mathrm{X})$ ton & Dry waste $(\mathrm{Y})$ ton & PET waste $(\mathrm{T})$ ton \\
\hline Mean $(\mu)$ & 275580 & 79642 & 629.610 \\
Standard deviation $(\sigma)$ & 31231.400 & 15288.100 & 104.615 \\
\hline
\end{tabular}

Fig. 1. shows the processing path of municipal collected solid wastes, path in grey is the one used for deriving of mathematical model.

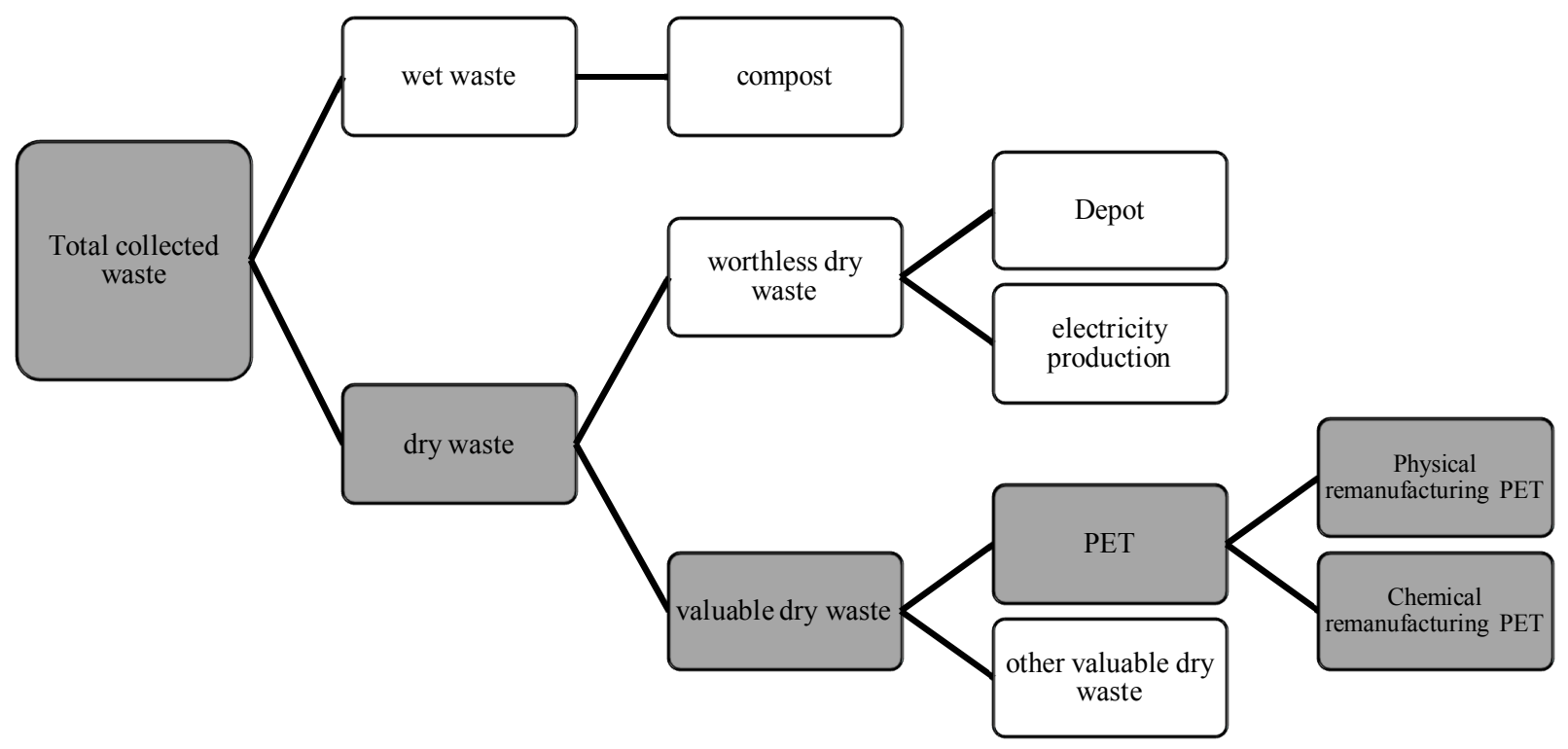

Fig. 1. The processing path of municipal collected solid wastes

Subsequent to deriving distribution function of collected waste, dry and PET waste, the next stage is deriving mathematical model, which is described in the following.

\subsection{The proposed model}

The proposed model is a Probabilistic non- linear one and the probability distribution function of waste amounts, is assumed to be normal. 


\subsection{Model Parameters}

$I=$ Set of fixed processing points,

$J=$ Set of fixed factory physical PET recycling points,

$K=$ Set of fixed factory chemical PET reproduction points,

$W_{i}=$ level of solid waste transported to the $i^{t h}$ processing complex,

$C a_{i}=$ maximum capacity of $i^{\text {th }}$ processing center,

$C a_{j}=$ maximum capacity of PET physical recycling plant,

$C a_{k}=$ maximum capacity of PET chemical reproduction plant,

$P_{p h}=$ return from sale of one kilogram physical recycled PET,

$P_{c h}=$ return from sale of one kilogram chemical reproduced PET,

$Z_{0}=$ probability distribution function for total municipal collected solid waste,

$Z_{l}=$ probability distribution function for dry waste separated from total municipal collected solid waste,

$Z_{2}=$ probability distribution function for separated PET from solid waste,

$d=$ the average fraction of dry waste obtained from the total municipal collected solid waste,

$f=$ the average fraction of PET obtained from solid waste,

$G_{i}=$ minimum amount of PET should be allocated to physical recycling plant $j$.

\subsection{Decision variables}

$X=$ total municipal collected sold waste,

$Y=$ total existing dry waste in municipal solid waste,

$T=$ total amount of PET in dry waste,

$P E T_{j}=$ amount of PET physically recycled in $j$ plant,

$P E T_{k}=$ amount of PET chemically reproduced in $k$ plant.

In this paper, we assume a plant is considered for the chemical reproduction plant represented by $\mathrm{k}$ and the number of working days is 26 days per month.

\subsection{Target function}

$\max Z=P_{p h} \sum_{j \in J} P E T_{j}+P_{c h} \sum_{k \in K} P E T_{k}$,

where Eq. (1) represents the maximization of return value obtained from physical recycling and chemical reproduction.

\subsection{Limitation}

$$
\begin{aligned}
& \sum_{i \in I} W_{i} \leq \sum_{i \in I} C a_{i} \\
& \sum_{j \in J} P E T_{j} \leq \sum_{j \in J} C a_{j}
\end{aligned}
$$




$$
\begin{aligned}
& \sum_{k \in K}^{104} P E T_{k} \leq \sum_{k \in K} C a_{k} \\
& \sum_{i \in I} W_{i}=X \\
& Z_{0}=\left(X-\mu_{X}\right) / \sigma_{X} \\
& Z_{1}=\left(Y-\mu_{Y}\right) / \sigma_{Y} \\
& Z_{2}=\left(T-\mu_{T}\right) / \sigma_{T} \\
& Y=d X \\
& T=f Y \\
& \sum_{j \in J} P E T j+\sum_{k \in K} P E T_{k}=T \\
& G_{j} \geq P E T_{j} \\
& X, Y, T, P E T_{j}, P E T_{k} \geq 0
\end{aligned}
$$

where Eq. (2) states that total amount of waste should not be higher than the total capacity of processing centers. Eq. (3) states that total amount of PET, which is physically recycled should not be higher than the total capacity of physical recycling plants. Eq. (4) states that total amount of PET, which is chemically reproduced should not be higher than the total capacity of chemical reproduction plants. Eq. (5) states that total sold waste are brought to processing center amounts to $X$. Eq. (6) represents the standard normal probability distribution function of municipal solid waste. Eq. (7) represents the standard normal probability distribution function of dry wise.

Eq. (8) represents the standard normal probability distribution function of municipal PET waste. Eq. (9) represents that the level of dry waste equals to $d$ percent of total municipal solid waste Eq. (10) is for total amount of PET waste equals to f percent of solid waste. Eq. (11) states that total amount of PET, which is physically recycled or chemically reproduced is equal to the total amount of PET waste. Eq. (12) states that $G_{j}$ is allocated to the physical recycling plant of $j$ at most (since the return from chemical reproduction is much more than physical recycling, this limitation is taken into account to avoid the zero value allocated to these plants). Finally, Eq. (13) states total municipal solid waste, dry waste and PET waste, which is physically recycled or chemically reproduced should be positive.

\subsection{Problem data}

$$
\begin{aligned}
& C a_{i}=182000 \text { ton, } i=1 ; \quad \sum C a_{j}=1500 \text { ton, } j=1, \ldots, 4 ; \quad C a_{k}=2000 \text { ton }, k=1 ; \\
& P_{p h}=1500000 \text { Toman (Local currency); } P_{c h}=6000000 \text { Toman (Local currency); } d=0.27 ; f=0.008 ; G_{j}=5 \text { Ton, } j=1, \ldots, 4 ;
\end{aligned}
$$

\subsection{Results from numerical solution of model and its analysis}

After deriving mathematical model, because our model is a probabilistic non-linear, we chose Lingo software to solve the resulted problem. Given the assumptions and data of the problem and Eqs. (113) as well as values of Table 1, the results from numerical solution of model are defined for decision variables. Two variables X, Y and T are 182,000 tons, 49,140 tons and 393.12 tons, respectively and the objective function is equal to $22,687,200$ Tomans, $\sum_{j=1}^{4} P E T_{j}=20$ and $P E T_{k}=373.12, k=1$. In other words, based on the obtained values, return of this model is 22,687,200,000 IRR. Moreover, 18,000 tons municipal solid waste was collected which equals to the $X$ value of which 49,140 tons allocated 
to dry waste $(Y)$ existed in municipal solid waste. Total amount of PET in dry waste $(T)$ is 393.12 including 373.12 tons $\left(\mathrm{PET}_{\mathrm{k}}\right)$ which is allocated to the chemical reproduction plant (based on the assumptions, $k=1)$ and 20 tons $\left(\mathrm{PET}_{\mathrm{j}}\right.$ ) or PET amount is allocated to physical recycling plants (based on the assumptions, $j=4)$. As we can see from the results, high percentage $(95 \%)$ of PET is allocated to the chemical reproduction, which represents its priority to the physical recycling. Furthermore, waste amounts are derived randomly through the solution of this mathematical model that will assists investments with the planning of production capacity.

\section{Conclusion and suggestions}

This study provided a probabilistic non-linear planning model for the chemical recycling of PET. Results from numerical solution of model have demonstrated that chemical recycling was highly beneficial and economic and environmentally effective in returning materials to consumption cycle. Other pollutions from lack of recycling and remaining of waste materials in nature will also be decreased.

According to the studies, since there is not any plant operating in the field of chemical recycling of PET in Iran, this field can be considered as a great opportunity for investment. Through the solution of mathematical model, we can conclude that we should benefit from the maximum capacity of chemical recycling plant. This proves that chemical recycling has the higher priority than physical recycling. We also suggest decision-making technic be involved in order to find a better way of chemical recycling of PET and then based on these technics, the best method will be determined. We further suggest this model be developed using fuzzy numbers and interval numbers and then compare the results with the current study. Moreover, we may obtain more accurate information for chemical recycling of PET through the expansion of model and introduction of limitation such as cost, distance and time.

\section{Acknowledgment}

The authors would like to thank the anonymous referees for construction comments on earlier version of this paper.

\section{References}

Abduli, M.A. (2008). Municipal Solid Waste Recovery. University of Tehran Press (In Persian).

Ahluwalia, P.K., \& Nema, A.K. (2006). Multi-objective reverse logistics model for integrated computer waste management. Waste Management \& Research, 24(6), 514-527.

Aras, N., Aksen, D., \& Gönül Tanuğur, A. (2008). Locating collection centers for incentivedependent returns under a pick-up policy with capacitated vehicles.European Journal of Operational Research, 191(3), 1223-1240.

Bautista, J., \& Pereira, J. (2006). Modeling the problem of locating collection areas for urban waste management. An application to the metropolitan area of Barcelona, Omega, 34(6), 617-629.

Liste, O., \& Dekker, R. (2005). A stochastic approach to a case study for product recovery network design. European Journal of Operational Research, 160(1), 268-287.

Omrani,Gh.A. (2010). Solid waste: content, Management, Collection, transportation, sanitary landfill and composting. Iran: Scientific Center of Islamic Azad University.

Ramezani, M., Bashiri, M., \& Tavakkoli-Moghaddam, R. (2012). A new multi-objective stochastic model for a forward/reverse logistic network design with responsiveness and quality level. Applied Mathematical Modelling, 37(1-2), 328-344.

Rhyner, C. R. (1995). Waste management and resource recovery. CRC Press.

Sheu, J. B. (2007). A coordinated reverse logistics system for regional management of multi-source hazardous wastes. Computers \& Operations Research, 34(5), 1442-1462. 
Zhang, Y. M., Huang, G. H., \& He, L. (2011). An inexact reverse logistics model for municipal solid waste management systems. Journal of Environmental Management, 92(3), 522-530. 